\title{
Quelques effets de la sincérité
}

Les réactions positives font du bien! Surtout lorsqu'on a conscience que les gens de ce pays sont plutôt portés aux commentaires négatifs, fâcheuse habitude qui fait écho à une mentalité bien helvétique, celle de considérer que «tant que personne ne réclame, c'est bon».

Et ces réactions font plus de bien encore lorsqu'on sait à quel point la sensibilité des organes responsables de la FMH aux questions de communication s'est développée, alors qu'il y avait un déficit notable dans ce domaine. Il y a deux ans, notre organisation faîtière s'était passablement éloignée de sa base. Une réputation désagréable de «Neinsager» affectait l'image de la FMH, souvent considérée comme opaque, peu constructive et mal profilée. La Chambre médicale a réagi - et le Comité central aussi.

Voici quelques échos à ce sujet:

Lors d'une manifestation organisée dernièrement par l'Université de Zurich, je me suis trouvé en contact avec des représentants de tous les secteurs du système de santé suisse. Des personnes bien informées et en provenance d'horizons les plus divers m'ont témoigné leur estime, en ma qualité de représentant de la FMH, ce qui m'a naturellement fait plaisir. Je transmets volontiers ici les louanges entendues: ces deux dernières années, la FMH est devenue plus communicative, on l'écoute et on la prend au sérieux car elle est devenue une organisation ouverte au dialogue, dotée d'une pensée constructive et prenant clairement position sur les sujets importants. Une expression est régulièrement apparue au cours des conversations, que ce soit avec le communicateur d'un grand hôpital, la collaboratrice d'une firme pharmaceutique réputée, des journalistes, des politiciens ou des scientifiques, qui est le mot «sincérité». Ou plus exactement, la «nouvelle sincérité» de la FMH.

Cette sincérité se retrouve aussi dans notre journal jaune, et nos lecteurs la comprennent bien comme telle: le Bulletin des médecins suisses que vous avez entre les mains est l'organe officiel de la FMH, hier comme aujourd'hui, et c'est notre outil le plus important pour communiquer avec nos membres (comme aussi avec un plus large public; en effet, notre journal est lu de manière croissante par des non-médecins!). La «communication» ne se borne cependant pas à transmettre des informations, dans la partie bleue, officielle, ou dans le reste du journal. Elle est aussi un échange, prisé par de nombreux lecteurs. Pour preuve, la dernière controverse sur les vaccinations, mais aussi toute la rubrique «Courrier du lecteur».

Notre sincérité se reflète encore dans la présence, forte et régulière, de la FMH à l'extérieur. Monde politique, groupes professionnels, tables rondes, médias: on veut connaître notre opinion chaque fois qu'un ordre du jour contient des thèmes de politique de la santé. Les débats menés actuellement au sujet du managed care et de l'obligation de contracter le montrent clairement.

Et en toute sincérité, nous en sommes très heureux!

Daniel Lüthi, responsable de la communication FMH 